\title{
Usability Testing of Online Movie Ticket Reservation in the Philippines
}

\author{
Mary Margaret F. Guzman (mfguzman@up.edu.ph)', Joyce Abigail B. Manaloto \\ (jbmanaloto@up.edu.ph) ${ }^{1}$, Anthony Dale DR. Senina (adsenina@up.edu.ph) ${ }^{1}$, Alyssa Jean A. Portus \\ (aaportus@up.edu.ph) ${ }^{1}$
}

${ }^{1}$ Department of Industrial Engineering and Operations Research, College of Engineering, University of the Philippines-Diliman, Quezon City 981-3128/981-3149

\begin{abstract}
SM Cinemas is one of the largest cinema chains in the country. SM has applied an online ticketing system in which users could reserve and buy tickets on their website. This study focuses on the usability of the SM Cinema website. Nine respondents were chosen to participate in the usability testing. Results show that the users were satisfied with the website's text and the activities done on the website are straightforward. However, the website was inefficient and users were unsatisfied with the layout of information presented. Moreover, users found difficulty when using the website for the first time. The users were also unsatisfied with some of the features and suggested numerous improvements. Recommendations were made and proposed in order to improve upon the usability of the website.
\end{abstract}

Keywords: Usability testing, Cinema tickets

\section{Introduction}

With the internet becoming a widespread commodity, online ticketing services are now also becoming increasingly available throughout different services.

Last November 2010, SM, one of the largest and most popular malls nationwide, has applied this online system of booking to further increase the efficiency and convenience of the customers in buying tickets. However, some issues have prevented it from becoming more accepted and used in the modern Filipino society. This study aims to analyze the usability of the online ticketing system used by SM Cinemas in order to make the system more user-friendly once it has been fully adopted by the Filipino society.

With the increasing popularity of online services, website quality is a critical step to improve business. In a study conducted on Chinese online visitors, it was determined, empirically, that website quality has a direct impact on customer satisfaction and purchase intention. [1] Another study, this time on the hotel sector, found website quality and website brand increased perceived trust and value which makes them more willing to purchase and continue the business relation. [2]
In a study examining 35 online stores, it was determined that a single-item measure for customer assessment was able to differentiate the usability of the online stores similar to an 9-item assessment. A positive correlation between the single item and intention to buy was identified, supporting the single-item measure. This supports that usability can be determined with a singleitem, removing the need for tedious multi item studies. [3]

Social media sites were successfully adopted and used for marketing purposes. The reason behind the success was assessed through usability testing and feedback from the users of its usefulness, and the resulting features were learnability and memorability. These features were also included in the metrics used in this SM cinema website usability study. [4]

A related study on the usability testing of cash-in machines for Filipinos used the anthropometric measurements of Filipinos as a basis for the ergonomic design of the cash-in machines. Assessment of the environment was also done to determine its suitability to the users. More importantly, this study also focused on the usability of the cash-in machines through evaluation of its efficiency, readability, layout, learnability, satisfaction and other additional features input in the surveys and it has been reported that there had been 
issues in machine control and environment. These parameters used for usability testing were also taken into consideration in this study of the SM Cinema website. [5]

A study on the usability and accessibility of three academic websites based on human-perception was conducted to know certain attributes that hinder the usefulness of the website. The usability testing was timed per task and the corresponding post-evaluation involved questionnaires asking for post-task satisfaction ratings, feedback, and observed task success rates. Its method of time measurement and content of the questionnaires used for post-testing is similar to this study of the SM Cinema website. [6]

Post-testing questions with regards to usability and its metrics of efficiency, readability, layout, learnability, interface, satisfaction and other additional features were based from the Website Analysis and Measurement Inventory (WAMMI) and IBM Computer Usability Satisfaction questionnaires. The questions require the subjects to rate the given statements by numbers with 1 being the lowest, and also equivalent for disagreement. Feedback was also taken into consideration to know what features need improvement. [7][8]

The number of participants used in the usability testing for the study was determined using the the $10 \pm 2$ rule put forward by Hwang and Salvendy stating that around eight participants are needed to be able to find and correct serious problems compared to the three participants needed if the purpose is simply to prove a need for usability testing. [9] On the other hand, the survey conducted as initial data gathering needed around 100 responses based on the recommended 83 by Bartlett, Kotrlik and Higgins population size of $10,000+$ with a $10 \%$ margin of error. [10]

\section{Method}

Usability testing shall be conducted to determine if there are problems regarding the website's usability, and if there are any, what the specific problems are focused on.

\subsection{Pre-Test (Survey)}

Data was taken from 100 samples by conducting surveys for the purpose of gauging their awareness of the existence of the website as well as their frequency of using the platform in relation to frequency of watching in SM Cinemas. [10]

\subsection{Testing proper}

The subjects were asked to perform two tasks: create an account and reserve cinema tickets online.

In order to create an account, the required information included an email address, a password, first and last names, a mobile number and account verification. For the account verification, the users will be required to check their emails to complete the transaction.

On the other hand, the steps in the online reservation of cinema tickets were the following: $\log$ in to an (already registered) account, selection of movie, branch and schedule, seat quantity then the mode of payment.

\subsection{Post-task}

After completion of each task, users will be asked to give feedback and rate their satisfaction with regards to the ease, amount of time, and support information in completing the task. The satisfaction was rated with 7 being highly satisfactory and 1 for vice-versa. Post-task questions are based on ASQ (After-Scenario Questionnaire). [4].

\subsection{Post-testing}

After all tasks, users are asked to rate their experience while using the website. Users were also asked what they thought was the best feature and what features need to be improved. Post-usability test questions are based on the WAMMI (Website Analysis and Measurement Inventory) questionnaire. [3]

The following metrics were included: Efficiency, Effectiveness, and Satisfaction.

\subsubsection{Efficiency}

The responsiveness of the website to the users is measured by the time and number of clicks the given tasks required and user feedback was collected.

\subsubsection{Effectiveness}

The capability of the website in producing the desired outcome as the users conduct any transaction such as registration and reservation. Different areas of effectiveness were rated by the users including Interface, Layout, Learnability, Features, and Readability 


\subsubsection{Satisfaction}

Satisfaction considers the user's overall happiness after using the website. Satisfaction was included and measured using the post-usability testing task questions from ASQ by ratings and feedback provided by the users.

\section{Results}

\subsection{Efficiency}

Mean time and mean number of clicks for each task are used as metrics to measure efficiency of the website. Efficiency was also rated by the participants garnering a mere 2.83 rating, rated lower than effectiveness which garnered a 3.36 rating, with four of the nine participants commenting that the site's efficiency was a problematic area. The registration process required a mean time of 1.41 minutes and an average of 11 clicks to complete. The process was generally well received with four of the nine usability participants commenting that the process was easy to perform. Users' suggestions on the registration process include improvement of the required captcha and improvement of the website's speed.

On the other hand, the reservation process needed an average of almost 4 minutes and 20 clicks to complete. Users found the reservation process to be more difficult compared to registration with only one user finding the process to be easy. The users also identified more areas for improvement including improvement of the layout of buttons, removal of glitches, simplification of the text and tabs, and improvement of the speed of the website.

Table 1. Mean time and number of clicks for each task

\begin{tabular}{lcr} 
& Registration & Reservation \\
\hline $\begin{array}{l}\text { Mean time } \\
\text { (minutes) }\end{array}$ & 1.41 & 3.59 \\
$\begin{array}{l}\text { Mean number } \\
\text { of clicks }\end{array}$ & 11 & 20
\end{tabular}

\subsection{Effectiveness}

Table 2. Mean ratings of each usability metric

\begin{tabular}{lr} 
Metric & Rating \\
\hline Features & 3.39 \\
Interface & 3.44 \\
Layout & 3.11 \\
Learnability & 3.00 \\
Readability & 3.89 \\
Mean Rating & $\mathbf{3 . 3 6}$
\end{tabular}

Based on Table 2, website effectiveness was rated an average of 3.36 with the most problematic metric of the website being learnability, with the lowest rating of 3.00 . While the least problematic area is readability with a rating of 3.89 .

\subsection{Satisfaction}

Table 4. Mean satisfaction ratings of tasks

\begin{tabular}{lrr} 
& Registration & Reservation \\
\hline $\begin{array}{l}\text { Ease of the task } \\
\begin{array}{l}\text { Duration of } \\
\text { completion }\end{array}\end{array}$ & 6 & 4.89 \\
$\begin{array}{l}\text { Support } \\
\text { information }\end{array}$ & 4.89 & 3.89 \\
Mean & 6.22 & 4.67 \\
& $\mathbf{5 . 7 0}$ & $\mathbf{4 . 4 8}$
\end{tabular}

Satisfaction ratings were gathered using the ASQ from the testers. The users were more satisfied with the registration process than the reservation process. These are consistent with the results of the efficiency metrics, as the less amount of time and clicks it requires to finish a task (the more efficient the task), the more satisfied the users are after task completion.

Some of the features that users thought should be maintained are the ease of registration and the accessibility of some features. Meanwhile, users' suggested features are addition of a search box, improvement of programming and content layout, display of ticket prices, and truncation of amount of information presented. 


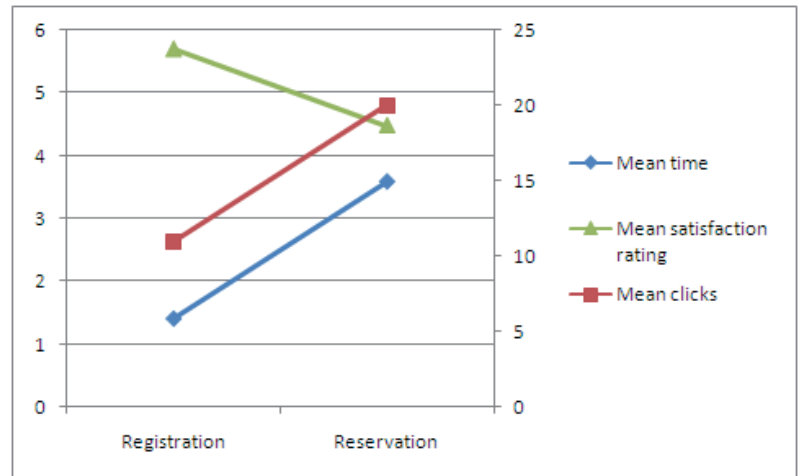

Figure 2. Plot of mean time and clicks vs. mean satisfaction rating

\section{Conclusion}

From the results of the tests conducted, the website is currently satisfactory. However, the online platform is still lackluster in areas of efficiency, and effectiveness. Improvements must be made to the website's layout, learnability, and features, as these are the most problematic areas for users.

In conclusion, one reason why this online platform is not widely utilized is because Filipino users are encountering too many problems in the usage of this online reservation platform of SM Cinemas.

\section{Acknowledgements}

The authors would like to thank Alyssa Jean Portus, their instructor and project adviser, for her time and effort in guiding them while conducting the study.

The authors would like to thank their parents for their support while the study was under process.

The authors would also like to thank their colleagues in the Department of Industrial Engineering and Operations Research in the University of the Philippines - Diliman, for their support and advice while the authors were conducting the study.

\section{References}

[1] Bai, B., Law, R., \& Wen, I. (2008). The impact of website quality on customer satisfaction and purchase intentions: Evidence from Chinese online visitors. International Journal of Hospitality Management, 27(3), 391-402. Chicago

[2] Chang, K. C., Kuo, N. T., Hsu, C. L., \& Cheng, Y. S. (2014). The Impact of Website Quality and Perceived Trust on Customer Purchase Intention in the Hotel Sector: Website Brand and Perceived Value as Moderators. International Journal of Innovation, Management and Technology, 5(4), 255. Chicago

[3] Christophersen, T., \& Konradt, U. (2011). Reliability, validity, and sensitivity of a single-item measure of online store usability. International Journal of Human-Computer Studies, 69(4), 269-280.

[4] Lacka, E., \& Chong, A. (2016). Usability perspective on social media sites' adoption in the B2B context. Industrial Marketing Management, $\quad$ 54, 80-91. doi:10.1016/j.indmarman.2016.01.001

[5] Canapi, J. M., Chan, M., Contreras, M. A., \& Portus, A. J. (2015). Usability Testing of Cash-in Machines for Filipino Use. Procedia Manufacturing, 3, 3486-3493. doi:10.1016/j.promfg.2015.07.657, http://ac.elscdn.com/S2351978915006587/1-s2.0-

S2351978915006587-main.pdf? tid=75231 fe6-a754-11e6add6-

$\underline{00000}$ aab0f26\&acdnat $=1478789366 \quad 699879 \mathrm{e} 6708 \mathrm{f} 2 \mathrm{~d} 4 \mathrm{be}$ $\underline{1 \mathrm{~b} 5 \mathrm{e} 37 \mathrm{aa} 6 \mathrm{a} 2 \mathrm{e} 400}$

[6] Roy, S., Pattnaik, P., \& Mall, R. (2014). A quantitative approach to evaluate usability of academic websites based on human perception. Egyptian Informatics Journal. Retrieved November 30, 2016.

[7] Claridge, J. K. (n.d.). WAMMI questionnaire. Retrieved November 29, 2016, from http://www.wammi.com/questionnaire.html

[8] After-Scenario Questionnaire. (n.d.). Retrieved November 29, 2016, from http://garyperlman.com/quest/quest.cgi?form=ASQ

[9] Wonil Hwang, Gavriel Salvendy Communications of the ACM, Vol. 53 No. 5, Pages 130-133 10.1145/1735223.1735255Comments (1), \& 11:46, J. 0 (n.d.). Communications of the ACM. Retrieved December 02, 2016, from http://cacm.acm.org/magazines/2010/5/87254-number-ofpeople-required-for-usability-evaluation/fulltext

[10] Bartlett, James E., Joe W. Kotrlik, and Chadwick C. Higgins. "Organizational research: Determining appropriate sample size in survey research." Information technology, learning, and performance journal 19.1 (2001): 43. 